\title{
TIMELY LESSONS FROM A PANDEMIC ON THE BENEFITS OF PERSON CENTRIC CARE IN LONG TERM CARE FACILITIES
}

\author{
S.-L. WEE ${ }^{1,2,3}$, P.L.K. YAP ${ }^{1,4}$ \\ 1. Geriatric Education and Research Institute (GERI), Singapore; 2. Health and Social Sciences Cluster, Singapore Institute of Technology (SIT), Singapore; 3. Programme in Health \\ Services and System Research, Duke-National University of Singapore (NUS) Medical School, Singapore; 4. Geriatric Medicine, Khoo Teck Puat Hospital (KTPH), Singapore. \\ Corresponding author: Shiou-Liang Wee, Geriatric Education and Research Institute (GERI), Singapore, weeshiouliang@gmail.com
}

\begin{abstract}
Since the outbreak of Coronavirus Disease 2019 (COVID-19), there have been few deadlier places than in nursing homes. As such, several useful guidelines on coping with COVID-19 in nursing homes have emerged. The critical immediate term measures mentioned in the guidelines have longer term implications especially on quality of care. We discuss how these measures instituted for infection control can be synergistic with person-centered care which has been synonymous with quality of care in nursing homes.
\end{abstract}

Key words: COVID-19, person-centred care, nursing home, infection control.

J Frailty Aging 2020;9(3)132-133

Published online May 22, 2020, http:/ / dx.doi.org/10.14283/jfa.2020.28

Vulnerability of residents in dormitory like nursing homes to COVID-19

The first case of Coronavirus Disease 2019 (COVID-19) in Singapore was confirmed in a tourist from Wuhan on 23 January 2020. Initial numbers grew in a relatively controlled manner given the prompt and coordinated public health measures in Singapore (1), with its contact-tracing praised by epidemiologists as "gold standard of near-perfect detection" (2). The first cluster of cases at a local nursing home (NH) surfaced on 1 April 2020, and quickly progressed by 23 Apr 2020 to five out of the total of 80 nursing homes in Singapore recording positive cases (3). Therefore, on 8 May, COVID-19 testing was instituted for all the 16,000 residents and 9,000 staff of all nursing homes (4). Frail and elderly nursing home residents, who are at highest risk of morbidity and mortality from COVID-19 (5), mostly reside in dormitory-like wards in Singapore and are cared for by staff who move freely between wards. The dire consequences of COVID-19 outbreaks in nursing homes in the Europe and US prompt deliberations on how better to care for vulnerable older people in long term care facilities during a pandemic, which have implications that extend to non-pandemic times too.

\section{Growing number of nursing homes, but what kind?}

As with many ageing nations, residential long term care in Singapore has become a pragmatic option for older persons who, for various reasons, cannot receive care appropriate for their needs at home. To meet this challenge, a comprehensive Healthcare Masterplan 2012-2020 has been progressively implemented in Singapore over the last decade with the endeavour to double the capacity of NHs (6). Besides accelerating the number of new and larger $\mathrm{NHs,} \mathrm{which} \mathrm{grew}$ from 64 in 2012 to 77 in 2019, there is also a desire to make a gradual transition from an institutional to a more home- like and person centric care model to better meet the needs of future cohorts of increasingly educated seniors who value greater privacy and autonomy. It is noteworthy that the recent guidelines (7-9) on coping with COVID-19 in long term care can have bearings on person centred care (10) (PCC) and the converse applies likewise.

\section{Synergism in infection control and person centred care}

For many NHs in our setting, including the one with the first COVID-19 cluster, dormitory style living with up to eight beds in a cubicle is still the norm in government subsided facilities. Single rooms are few and meant for immuno-compromised residents or isolation of those with infectious diseases. Single rooms housed within small and home-like environments, which afford greater privacy, freedom and personalisation of space, is aligned with PCC and have been evidenced to be associated with less agitation, and better mood and sleeping patterns in people with dementia (11). PCC also promotes autonomy where residents are self-caring as far as possible and encouraged to engage in higher order tasks to maintain a sense of meaning and purpose, and to optimize functional capabilities. Having more independent residents is advantageous during a pandemic given the need for isolation and safe distancing, with decreased staff-resident contact time. These measures for infection control can conceivably be continued beyond the pandemic in the form of single rooms to secure an enhanced living ambience for the residents and respects their right to individuality and selfdetermination.

A dormitory-like living arrangement, with frequent staff movement between shifts and wards, can promote depersonalised care as staff have less opportunities to acquaint themselves well with the residents and build relationships. These relatively more expansive living spaces with limited staffing often prioritise safety above autonomy whereby frail residents who attempt to get out of bed on their own 


\section{THE JOURNAL OF FRAILTY \& AGING}

are restrained to prevent falls. In contrast, small and homelike environments, with consistent staff caring for the same residents, help to promote closeness and nurture relationships which are fundamental to the wellbeing of both residents and staff. Moreover, having the same staff care for a smaller group of residents has the advantage of reducing the risk of cross-infection during an outbreak. The intimacy and trust developed over time also lends itself more expediently to honest conversations on which advance care plans are founded. Making advance care plans is pertinent in the face of a pandemic like COVID-19 (12) which preferentially increases mortality in frail nursing home residents. A 90 year old woman from Belgium made the decision to refuse ventilator treatment during the current pandemic, saying "Keep this for the younger patients, I have had a beautiful life" (13).

\section{Harnessing technology application}

Regular human interaction and engagement are crucial to PCC. This becomes highly challenging to fulfil with the need for physical distancing and infection control. COVID-19 has seen the application of several available technologies. Likewise, technologies can be relevant in long term care and especially useful in a pandemic. Autonomous robots have been deployed in COVID-19 isolation rooms to deliver meals and medication, monitor vital signs and act as portals of communication between staff and patients (14). If single rooms for PCC are advocated, these robots can be adopted and the residents given time to familiarise so that even those with dementia will not be averse to interacting with them. The digital interface, delivered through robots or video conferencing, can also prompt reminders for daily activities, engage residents in therapy and interactive games, and provide opportunities for conversations with staff, family and friends. Hence, pre-emptive adoption of technology in long term care can ease transition into more technology enabled care during pandemic times. Conversely, the uptake of technology during a pandemic can also facilitate more sustainable use of technology beyond the pandemic.

\section{Conclusion}

Recently, we completed a study on "Rethinking the design of nursing homes". Part of the study involved several local NHs which included an early adopter of PCC which had instituted systematic enhancements in the built environment and care culture of the organisation (15). Preliminary results showed promising improvements in the residents' overall well-being. If COVID-19 has sparked the best of human compassion, ingenuity and adaptability; we hope the exchange of learnings from PCC and COVID-19 can bring about better care to enhance well-being in residents of nursing homes.

Conflicts of Interest: The authors declare no conflict of interest.

\section{References}

1. Wong JEL, Leo YS, Tan CC. COVID-19 in Singapore-Current Experience: Critical Global Issues That Require Attention and Action. JAMA. 2020;323(13):1243-1244. doi:10.1001/jama.2020.2467

2. BBC News (19 March 2020). Coronavirus: The detectives racing to contain the virus in Singapore. https://www.bbc.com/news/world-asia-51866102. Accessed $27 \mathrm{Apr}$ 2020 .

3. Straits Times (23 Apr 2020). Two new nursing home infections bringing total to five homes with COVID-19 cases. https://www.straitstimes.com/singapore/two-newnursing-home-infections-bring-total-to-five-homes-with-covid-19-cases. Accessed 12 May 2020.

4. Channel News Asia (8 May 2020). https://www.channelnewsasia.com/news/singapore/ covid-19-testing-nursing-home-residents-employees-ren-ci-amk-12714984.

5. Comas-Herrera A, Zalakain J, Litwin C, Hsu AT, Lane N and Fernandez-Plotka J-L. Mortality associated with COVID-19 outbreaks in care homes: early international evidence [monograph on the Internet]. International Long-Term Care Policy Network 2020. https://ltccovid.org/2020/04/12/mortality-associated-with-covid-19-outbreaksin-care-homes-early-international-evidence/. Accessed 12 May 2020.

6. WHO File Repository. Singapore healthcare masterplan 2012-2020. https://extranet. who.int/countryplanningcycles/sites/default/files/planning_cycle_repository/singapore/ singapore_healthcare_masterplan_2020.pdf. Accessed 23 Apr 2020.

7. Dosa D, Jump RLP, LaPlante K and Gravenstein S. Long-term care facilities and the coronavirus epidemic: practical guidelines for a population at highest risk. Journal of the American Medical Directors Association (2020). https://doi.org/10.1016/j. jamda.2020.03.004

8. RM Lynch and R Goring. Practical Steps to Improve Air Flow in Long-Term Care Resident Rooms to Reduce COVID-19 Infection Risk. Journal of the American Medical Directors Association (2020). https://doi.org/10.1016/j.jamda.2020.04.001

9. World Health Organization (2020). Infection prevention and control guidance for longterm care facilities in the context of COVID-19: interim guidance, 21 March 2020 World Health Organization. https://apps.who.int/iris/handle/10665/331508. License: CC BY-NC-SA 3.0 IGO.

10. GHZ Wong, WS Pang and PLK Yap. A paradigm shift in regulating and running nursing homes in Singapore. Journal of the American Medical Directors Association 15 (2014) 440-4. http://dx.doi.org/10.1016/j.jamda.2013.12.082

11. Fleming, R. \& Purandare, N. (2010). Long-term care for people with dementia: environmental design guidelines. International Psychogeriatrics, 22 (7), 1084-1096. https://doi.org/10.1017/S1041610210000438

12. BL Block, AK Smith, RL Sudore. During COVID-19, Outpatient Advance Care Planning is Imperative: We need All Hands on Deck. JAGS 2020. Published: 02 May 2020. https://doi.org/10.1111/jgs.16532

13. The Brussels Times (1 April 2020). https://www.brusselstimes.com/belgium/104108/ coronavirus-belgian-woman-90-dies-after-refusing-ventilator/. Accessed 26 Apr 2020

14. Today (5 March 2020). https://www.todayonline.com/singapore/robot-deliver-mealsmedication-covid-19-patients-alexandra-hospital-reduce-exposure. Accessed 27 April 2020.

15. Urban Redevelopment Authority (URA) Skyline Issue 12. Rethinking the design of nursing homes. https://www.ura.gov.sg/Corporate/Resources/Publications/Skyline/ Skyline-issue12/Rethinking-design-of-nursing-homes. Accessed 27 April 2020. 